\title{
Laser ablation ICP-MS for quantitative biomedical applications
}

\author{
Ioana Konz • Beatriz Fernández • M. Luisa Fernández • \\ Rosario Pereiro • Alfredo Sanz-Medel
}

Received: 27 February 2012 /Revised: 27 March 2012 / Accepted: 4 April 2012 / Published online: 29 April 2012

(C) Springer-Verlag 2012

\begin{abstract}
LA-ICP-MS allows precise, relatively fast, and spatially resolved measurements of elements and isotope ratios at trace and ultratrace concentration levels with minimal sample preparation. Over the past few years this technique has undergone rapid development, and it has been increasingly applied in many different fields, including biological and medical research. The analysis of essential, toxic, and therapeutic metals, metalloids, and nonmetals in biomedical tissues is a key task in the life sciences today, and LA-ICP-MS has proven to be an excellent complement to the organic MS techniques that are much more commonly employed in the biomedical field. In order to provide an appraisal of the fast progress that is occurring in this field, this review critically describes new developments for LA-ICP-MS as well as the most important applications of LA-ICPMS, with particular emphasis placed on the quantitative imaging of elements in biological tissues, the analysis of heteroatom-tagged proteins after their separation and purification by gel electrophoresis, and the analysis of proteins that do not naturally have ICP-MS-detectable elements in their structures, thus necessitating the use of labelling strategies.
\end{abstract}

Published in the special issue Young Investigators in Analytical and Bioanalytical Science with guest editors S. Daunert, J. Bettmer, T. Hasegawa, Q. Wang and Y. Wei.

I. Konz $\cdot$ B. Fernández $(\triangle) \cdot$ M. L. Fernández $\cdot$ R. Pereiro $\cdot$

A. Sanz-Medel

Department of Physical and Analytical Chemistry,

Faculty of Chemistry, University of Oviedo,

Julian Clavería 8,

33006 Oviedo, Spain

e-mail: fernandezbeatriz@uniovi.es

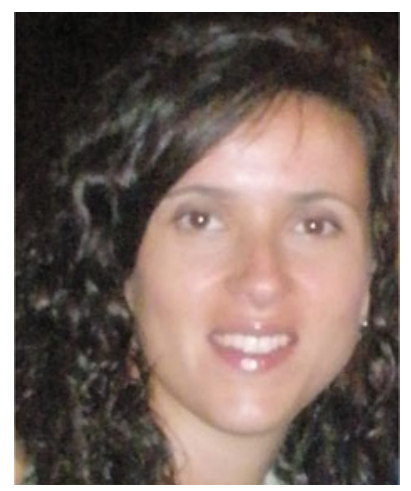

Beatriz Fernandez

obtained her European Ph.D. in 2006 at the University of Oviedo (Spain). She was awarded the Extraordinary Doctorate Prize (Analytical Chemistry) of the University of Oviedo and the San Alberto Magno Doctoral Thesis Award. Between 2006 and 2008 she was a postdoctoral researcher in the Laboratory of Bio-inorganic and Environmental Analytical Chemistry at the IPREM in Pau (France). Since September 2008 she has performed postdoctoral research in the Analytical Spectrometry Group in the Department of Physical and Analytical Chemistry of Oviedo University. Her main scientific interests are related to optical and mass spectrometry techniques for the direct analysis of solid materials. Her current research is mainly focused on elemental/molecular analysis of nanomaterials and thin films using GD-OES and GD-MS, and the analysis of biomedical, geological, and industrial samples by LA-ICP-MS.

Keywords Laser ablation inductively coupled plasma mass spectrometry $\cdot$ Gel electrophoresis · Quantitative bioimaging of heteroatoms $\cdot$ Heteroatom-tagged protein analysis $\cdot$ Protein labelling

\section{Introduction}

In recent years, much research effort has been directed towards the comprehensive study of metalloproteins, and many advances have been made in this field, mainly in relation to protein structures, metal site and function, and biological implications of metal-biomolecule interactions [1]. The great analytical challenge in this area is to combine specificity with high sensitivity. This is often difficult to achieve because of the complex compositions of biomedical 
samples and the low concentration levels of the species of interest.

Mass spectrometry (MS) techniques offer great potential for the analysis of proteins and metalloproteins because they can provide unique elemental and molecular information that is of great value for enhancing our understanding of the roles of proteins in biological systems [2]. However, quantitative protein analysis is still one of the main challenges in the analytical and bioanalytical sciences [3]. Among the MS techniques available, laser ablation inductively coupled plasma mass spectrometry (LA-ICPMS) is currently regarded as one of the most versatile inorganic MS tools for trace element and isotopic analyses of solids, including the analysis of heteroatom-tagged proteins in biological and medical tissues. The most striking features of LA-ICP-MS are its ease of use, high sensitivity, and its dynamic range, which covers up to twelve orders of magnitude, allowing the simultaneous acquisition of major, minor, and trace element constituents. Other useful features are its high spatial resolution $(<1 \mu \mathrm{m})$ and small material uptake $(<0.1 \mu \mathrm{g} / \mathrm{s})$, which means that it is virtually nondestructive to samples on the macroscopic scale [4].

Biological heteroatom-relevant information can be addressed at different levels. Most often, bulk elemental analysis is carried out, so trace elements are determined after homogenisation of the biological sample, usually after an acid digestion. However, this approach is limited in many instances because it ignores not only the speciation of an element but also its spatial distribution. It can be stated that the meaning and value of trace element information in biological environments increases with the analytical sampling resolution, placing strict requirements on both the sensitivity and spatial resolution of the detection technique [5]. In this sense, during the last decade, LA-ICP-MS has established itself as a powerful tool for performing information-rich elemental analyses of biomedical samples.

The purpose of this review is to evaluate the progress of, recent developments in, and the most relevant applications of LA-ICP-MS for quantitative biomedical science and protein analysis. Thus, particular attention is paid to analytical quantification strategies, focusing on three areas of activity: elemental imaging in tissues, the analysis of naturally heteroatomtagged proteins after their separation by gel electrophoresis, and the analysis of proteins that do not naturally possess ICPMS-detectable elements in their structures, thus making it necessary to resort to labelling strategies.

\section{Bioimaging of heteroatoms by LA-ICP-MS}

Bioimaging analytical techniques are currently of great interest in life science studies, and have been rapidly growing in popularity for biomedical applications $[6,7]$. To achieve a deeper understanding of complex biological processes at a tissue level, adequate analytical tools with spatial resolution in the nanometre region are increasingly needed. In this vein, LA-ICP-MS has demonstrated great potential, as it allows the spatially resolved analysis of heteroatoms (especially metals) in different types of tissues, including mouse kidney and heart tissues $[8,9]$, human lymph nodes and respiratory tissues $[10,11]$, as well as liver biopsy, breast cancer, and prostate tissues $[12,13]$. The first work to report the analysis of fresh soft tissues by LA-ICP-MS was published in 2002 by Feldmann et al. [14], and it focussed on the analysis of thin sections of lamb's liver and kidney. The proof-of-concept for two-dimensional (2D) mapping was then reported for the analysis of $\mathrm{Cu}$ and $\mathrm{Zn}$ in sheep liver sections [15], showing the potential of LA-ICP-MS for the determination of nonuniform spatial distributions of elements throughout tissues. Since its introduction, LA-ICPMS has found increasing use in studies of heteroatom distributions in biomedical tissues. In general, microlocal analysis is performed to study the accumulation of certain heteroatoms in the regions of interest, as well as to compare the distributions of different elements between control and diseased tissue.

In the last few years, LA-ICP-MS has been widely employed for metal and nonmetal imaging in brain tissue sections by the groups of McLeod [16], Doble [17, 18] and, particularly, Becker [19-23]. Metal accumulations in the brain appear to be directly linked to neurodegenerative processes (e.g. Alzheimer's, Parkinson's, or Wilson's diseases, ageing and ischaemia). Therefore, bioimaging of selected heteroatoms is a challenging (particularly in relation to metal quantification) and emerging field in brain research. Zoriy et al. [19] reported the quantitative imaging by LA-ICP-MS of element distributions in histological sections of glioblastoma multiforme, the most common primary human brain tumour. Frozen tissue sections were prepared from three different human glioblastoma specimens, and matrix-matched laboratory standards with defined concentrations of the analytes were prepared for calibration purposes. The $\mathrm{Cu}$ and $\mathrm{Zn}$ distributions showed similar localisations, which histologically corresponded to areas of intratumoral haemorrhage. Interestingly, both elements were found to be absent within the tumour. Moreover, the concentrations of all of the measured elements were lower in the glioblastoma multiforme tissue than in the control brain. In another quantification report, Matusch et al. [24] showed the potential of LA-ICP-MS to produce large series of quantitative maps of $\mathrm{Cu}, \mathrm{Zn}, \mathrm{Fe}$, and $\mathrm{Mn}$ in native brain sections of mice that were subchronically intoxicated with the neurotoxin 1-methyl-4-phenyl-1,2,3,6-tetrahydropyridine (MPTP), as a model of Parkinson's disease. A defined sample area of brain tissue was ablated line by line with a focussed laser beam, and the distribution profiles of the metals were quantified using matrix-matched synthetic 
laboratory standards. These calibration standards were prepared from brain homogenates of analogous control mice doped with the trace elements of interest at defined concentrations. Figure 1 shows quantitative LA-ICP-MS images reported for $\mathrm{Cu}, \mathrm{Zn}$, and $\mathrm{Fe}$ in brain sections from mice treated with the neurotoxin MPTP ( 2 h, 7 days, and 28 days after the last injection) compared to controls. Metal enrichments in different areas of the brain were observed in diseased mouse compared to the control brain.

So far, most of the quantitative works related to the imaging of heteroatoms in biomedical tissues by LA-ICP-MS have utilised synthetic laboratory standards for quantification. However, this is one of the most controversial aspects of quantitative imaging studies, from our point of view, due to the complexity of the sample matrix: careful control of the tissue thickness, water content, and density of each tissue region is required when synthesizing and selecting standards in order to avoid differences in the real laser-matter interaction and thus obtain precise and accurate measurements. Some critical points relating to the sample preparation step, the selection of instrumental parameters, and, particularly, reported normalisation approaches and quantification strategies when performing quantitative imaging by LA-ICP-MS are critically discussed in the following sections.

\section{Sample preparation}

The analysis of soft tissue samples by LA-ICP-MS is generally carried out using either paraffin-embedded or native frozen (stored at temperatures of around $-70{ }^{\circ} \mathrm{C}$ ) sections. The samples are sliced to about $20-200 \mu \mathrm{m}$ in thickness and deposited on a flat surface (e.g. a glass slide). Both the thickness of the tissue and the laser parameters should be optimised for each specific application in order to ensure complete ablation of the tissue of interest, thus guaranteeing reproducible analyses. For the analysis of dried tissues, the laser ablation process can be performed at room temperature. However, the application of cooled laser ablation cells (commercially available from selected laser ablation companies or developed in research laboratories) has proved to be advantageous, not only for the analysis of cryopreserved materials, but also for dried biological samples [25, 26].

Two types of cooled ablation cells, developed originally by the working groups of Feldmann and Becker [14, 26], have been successfully employed for the elemental bioimaging of soft tissues [8, 15, 25]. Figure 2 shows schematic diagrams of these two ablation cells. Feldmann et al. [14] proposed a cryogenically cooled ablation cell with a temperature sensor and a copper cooling coil in the bottom of the cell. The sensor is connected to a temperature controller, which regulates the liquid nitrogen supply (stored in a dewar) to the ablation cell by a solenoid valve. In this case, the temperature can be controlled from $-20{ }^{\circ} \mathrm{C}$ to $-100{ }^{\circ} \mathrm{C}$. On the other hand, Becker et al. [27] developed a cooled laser ablation cell. The cooling system is arranged such that two Peltier elements are connected serially under the target holder, made of Al. Using this setup, a target holder temperature of about $-15^{\circ} \mathrm{C}$ was observed. The use of cooled ablation cells led to higher signal stability and better sensitivity than seen for room temperature measurements, thus yielding precise and accurate analytical data.

However, most of the imaging studies reported by LAICP-MS are still carried out at room temperature, probably due to the high cost of commercial cooled systems. On the other hand, it should be noted that in both types of commercially available cells, the sensors do not measure the actual temperature of the sample - only that of the ablation cell surface. The measurement of sample temperature in situ is desirable, as it would allow better and faster control of the temperature in order to preserve sample integrity and the
Fig. 1 Quantitative metal images of $\mathrm{Cu}, \mathrm{Zn}, \mathrm{Fe}, \mathrm{Mn}$ representative of each group (control, 2 h, 7 days, and 28 days after the last of five daily MPTP injections).

Sections obtained at a posterior level crossing the substantia nigra, the interpeduncular nucleus, and the hippocampus. From [24]; reproduced with the permission of the American Society for Mass Spectrometry

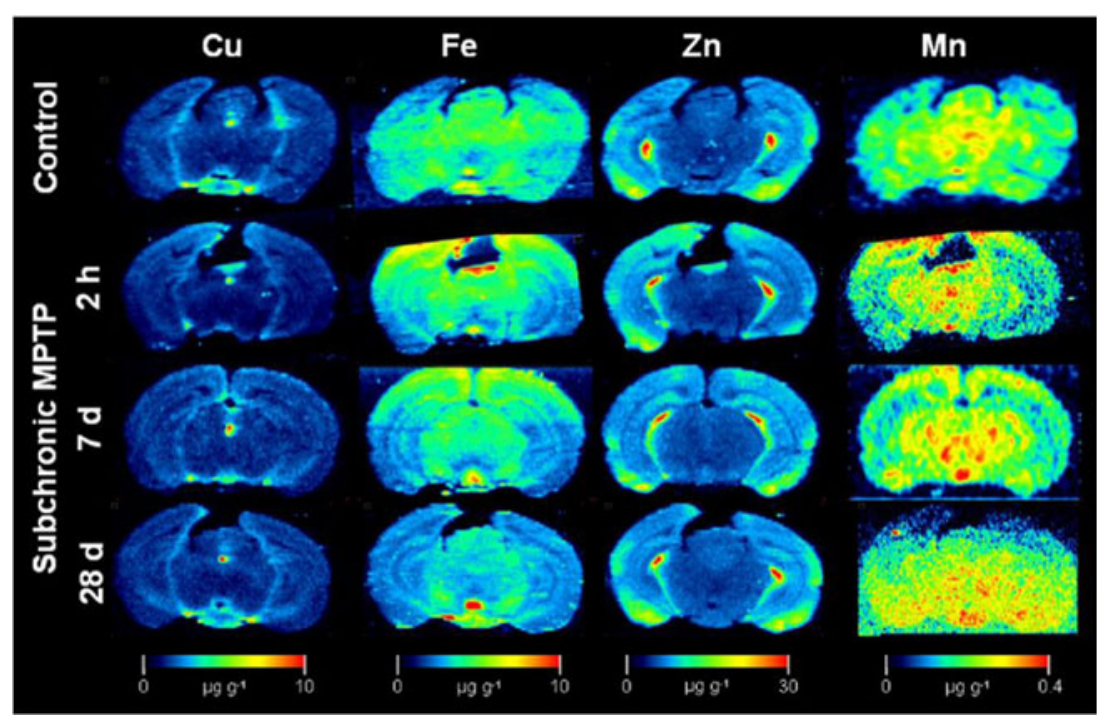


a

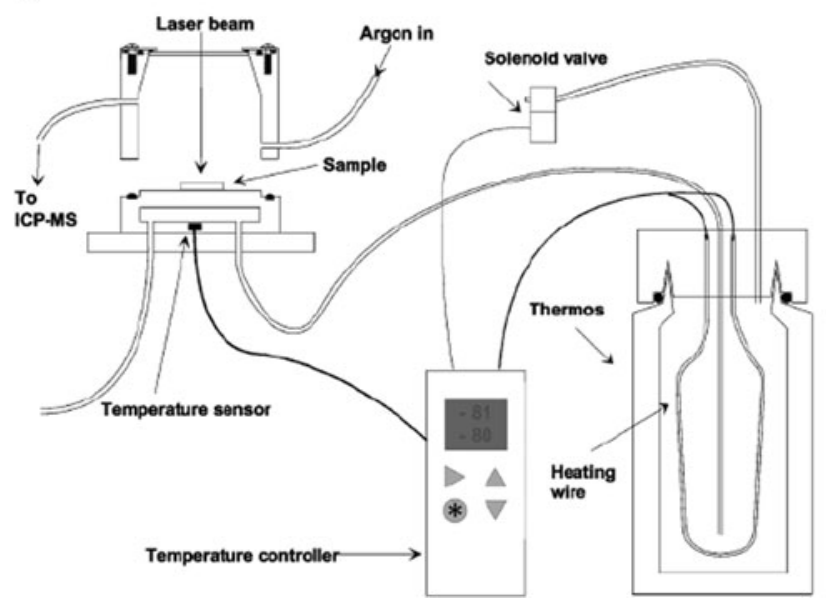

b

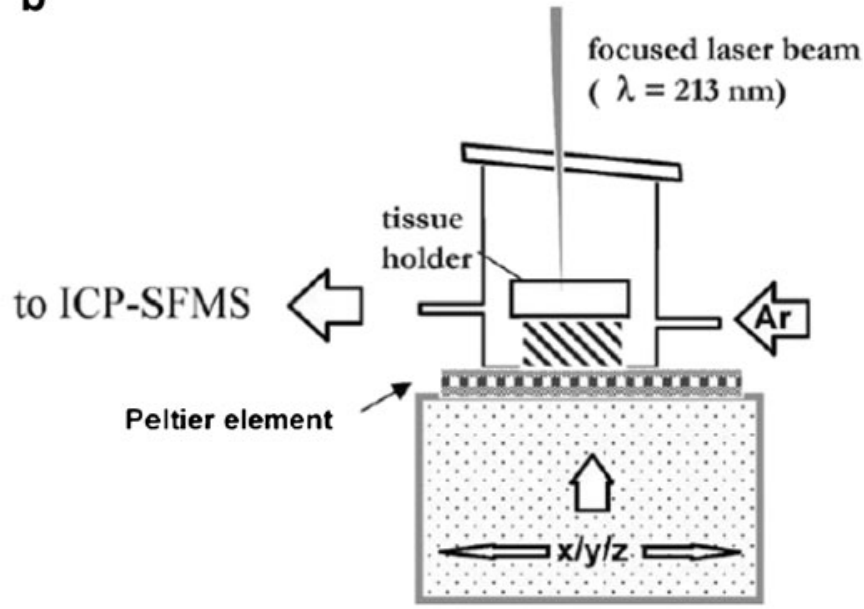

Fig. 2 a-b Schematics of the cryogenically cooled ablation cell (a) and the cooled PFA chamber (b) as proposed by the working groups of Feldmann and Becker, respectively. From [14, 27]; reproduced with the permission of The Royal Society of Chemistry

analytical conditions during the measurements (acquisition times of up to $30 \mathrm{~h}$ can easily be required for high-resolution imaging studies).

Optimisation of the laser and ICP-MS parameters

Despite the development of LA-ICP-MS for the imaging of elements in different types of tissues, spatial resolution, sensitivity, and data acquisition speed remain the main hurdles to achieving high-resolution images. Concerning spatial resolution, LA-ICP-MS analyses can easily be carried out using a $10 \mu \mathrm{m}$ spot size, but achievable spatial resolution also depends on the integration time used and the washout time (through all of the transport system, including the ablation cell and transport tubing) of the laser-generated aerosol. Moreover, typical data acquisition times for a $5 \mathrm{~mm}^{2}$ specimen can vary from over $2 \mathrm{~h}$ for a low-resolution image to more than $30 \mathrm{~h}$ for a more detailed image. As certain applications require high resolution, LA-ICP-MS requires significant reductions in analysis time to stay at the forefront of accessible $\mu \mathrm{m}$-scale elemental imaging technology. Thus, the laser and ICP-MS parameters must be carefully selected for each particular sample to optimise the analytical conditions in terms of sensitivity, spatial resolution, and analysis time. Lear et al. [28] have recently investigated the relationship between laser scan speed, MS dwell time, and image resolution for the purpose of speeding up typical total acquisition times for constructing images of mice brain sections. It was observed that the original relative dimensions of the samples are maintained in LA-ICP-MS images if the laser scan speed is equal to the laser spot diameter divided by the scan cycle time in the MS. Thus, the maximum laser scan speed may be calculated from the dwell time, the number of $\mathrm{m} / \mathrm{z}$ measured, and the detection limits required.
An interesting comparison between the elemental imaging capabilities of LA-ICP-MS and micro X-ray fluorescence (XRF) spectrometry was carried out for the model organism Daphnia magna, in terms of detection power and spatial resolution, by Gholap et al. [29]. Experimental results showed that the spatial resolution of LA-ICP-MS seems to be higher than that provided by micro-XRF. However, washout effects and spikes disturb the quality of the ICP-MS image to some extent. In the same way, Wang et al. [30] recently reported a complementary method for the high spatial resolution imaging of trace elements in heterogeneous media using LA-ICP-MS and synchrotron micro-XRF. It was observed that combining the outputs achievable by the two independent techniques enhances the imaging capabilities significantly. Nevertheless, it should be noted that the efficiency obtained using LA-ICPMS measurements was comparatively low due to the slow washout of the ablation cell. In brief, a faster aerosol transportation system (to improve the spatial resolution) and the avoidance of signal deconvolution of experimental data (which has necessary up to now to obtain higher-quality imaging by decreasing the contribution of shot-to-shot overlap) would be aimed at.

\section{Signal normalisation approaches}

Different internal standards (IS) have been investigated for both qualitative and quantitative elemental bioimaging using LA-ICP-MS in order to account for matrix effects as well as variations in ablated mass, transported mass, and instrumental drift. An effective IS should behave in a similar manner to the analyte during the ablation process, during transport, and in the ICP. Additionally, it should be homogeneously distributed within the sample, which is one of the critical requirements to obtain accurate measurements in biomedical tissues. More conventional approaches to internal normalisation in elemental 
bioimaging applications employ the ${ }^{13} \mathrm{C}$ signal $[10,15,21]$. However, ${ }^{13} \mathrm{C}$ is not always homogeneously distributed within the different structures of soft tissues, so it does not entirely satisfy the requirements of an IS. Moreover, ${ }^{13} \mathrm{C}$ is less sensitive to instrumental fluctuations than the analytes under investigation [31, 32].

Austin et al. [33] have recently reported a detailed study on the factors (e.g. laser spot diameter, mass bias, and cell sampling position) that affect IS selection for quantitative bioimaging of soft tissues. In that work, analyses of homogenised chicken breast sections were performed using ${ }^{13} \mathrm{C},{ }^{52} \mathrm{Cr},{ }^{53} \mathrm{Cr}$ and ${ }^{101} \mathrm{Ru}$ as internal standards. No single element was an ideal IS for all analytes; however, it was observed that normalisation greatly improved precision provided that the selected IS had a uniform distribution. Results showed that ${ }^{13} \mathrm{C}$ could be an acceptable IS for elemental bioimaging applications.

A new approach to elemental bioimaging by LA-ICP-MS that uses thin polymeric films spiked with elemental standards of the analytes and well selected ICP-MS internal standards ( $\mathrm{Ru}$ and $\mathrm{Y})$ as calibration standards has been recently proposed [34]. The tissue sample can be placed on top of a thin film containing an adequate IS. The use of $\mathrm{Ru}$ and $\mathrm{Y}$ internal standards improved the accuracy of quantification by LA-ICP-MS (whether no IS was used, or ${ }^{13} \mathrm{C}$ was employed as the IS).

\section{Quantification strategies}

Probably the more serious limitation of LA-ICP-MS for elemental bioimaging is the lack of reliable validated quantification strategies. On-line solution-based calibration has been investigated for quantitative analysis $[25,35]$. The dual sample/standard approach was proposed to produce quantitative information in the absence of solid calibration standards: the laser-generated aerosol is combined with the aerosol generated by solution nebulisation of an aqueous calibration standard. Becker et al. reported two different solution-based calibrations for the bioimaging of heteroatoms in brain sections by inserting a micronebuliser into the laser ablation cell [25] and by introducing the two aerosols separately in the injector tube inside a special ICP torch [35]. In the first case, during the laser ablation of tissue, defined standard solutions with increasing concentrations were nebulised. In the second option, the dry aerosol produced by laser ablation of the sample and the wet aerosol generated by pneumatic nebulisation of standard solutions are carried by two separated flows of $\mathrm{Ar}$ and introduced directly into the injector tube of the ICP through two different apertures. The authors concluded that employing on-line solution-based calibration procedures leads to more standardised plasma conditions, and it buffers against the detrimental effects of sample loading. Obviously, these proposed external calibration approaches consider neither possible tissue inhomogeneities nor the different interaction between the laser beam and the biomedical tissue.

Most quantitative studies have relied upon certified reference materials (CRMs) or, especially, the preparation of matrixmatched laboratory standards. Examples of the former include the use of a CRM (LGC 7112) for single-point calibration in the quantification of trace elements in sheep liver [14] or the use of pressed pellets of CRMs (TORT-2, DOLT-2 and DORM-2) for the quantification of $\mathrm{Cu}, \mathrm{Zn}$ and $\mathrm{Fe}$ in rat brain sections [31]. However, the most commonly employed calibration strategy is based on the use of matrix-matched standards prepared by spiking the tissues of interest with known amounts of aqueous standards [8, 19-22, 36-38]. Briefly, a set of matrix-matched homogenised laboratory standards with defined elemental concentrations are prepared. The homogenised tissue standards are frozen and cut into $20-100 \mu \mathrm{m}$ sections and mounted on glass slides. The set of laboratory standards and the tissue are then analysed under the same experimental conditions. The final elemental concentrations in the prepared standards are verified (e.g. by ICP-MS) and their homogeneities can be investigated using LA-ICP-MS. Becker et al. [25] reported regression coefficients of the calibration curves of $>0.9$ using this methodology for the analysis of $\mathrm{P}, \mathrm{S}, \mathrm{Fe}, \mathrm{Cu}$, $\mathrm{Zn}$, Th, and $\mathrm{U}$ in human brain samples. Nevertheless, it should be noted that this strategy does not take into account the inhomogeneity of the biomedical tissues and possible differences in water content and density within one tissue, so it is not possible to guarantee similar behaviour of samples and standards during the ablation process, during the transport of the laser-generated aerosol, and inside the ICP.

Two novel calibration approaches have been recently proposed for the quantitative elemental imaging of biomedical tissues by LA-ICP-MS. Austin et al. [34] investigated the use of thin film coated calibration standards prepared by spin coating for the quantification of $\mathrm{Cu}$ and $\mathrm{Zn}$ in chicken breast tissue. The tissues of interest were quantified using the calibration curves from the spin-coated standards (metalspiked polymethylmethacrylate films) using $\mathrm{Y}$ and $\mathrm{Ru}$ as ISs. Figure 3a illustrates the concept of ablating the sample together with a film containing the IS and the workflow of the quantification process. The tissue samples were frozen and slices were cut precisely to a thickness of $20 \mu \mathrm{m}$ and placed on top of spin-coated quartz. It was observed that the polymer matrix ablated in a similar way to soft tissue samples, and provided a much simpler, faster, and more reliable quantification methodology in comparison to homogenised tissue standards. On the other hand, Pugh et al. [39] proposed an alternative strategy for the quantitative imaging of $\mathrm{Sr}, \mathrm{Gd}$, and Pt. The approach is relatively simple and is based on spiking whole blood or blood serum with known amounts of elemental standards. Enriched aliquots are then frozen in a customised block and subjected to cryomicrotoming, thus 


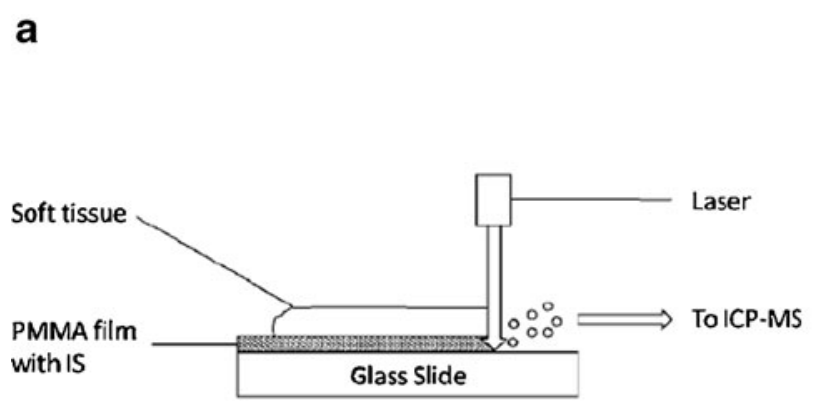

b

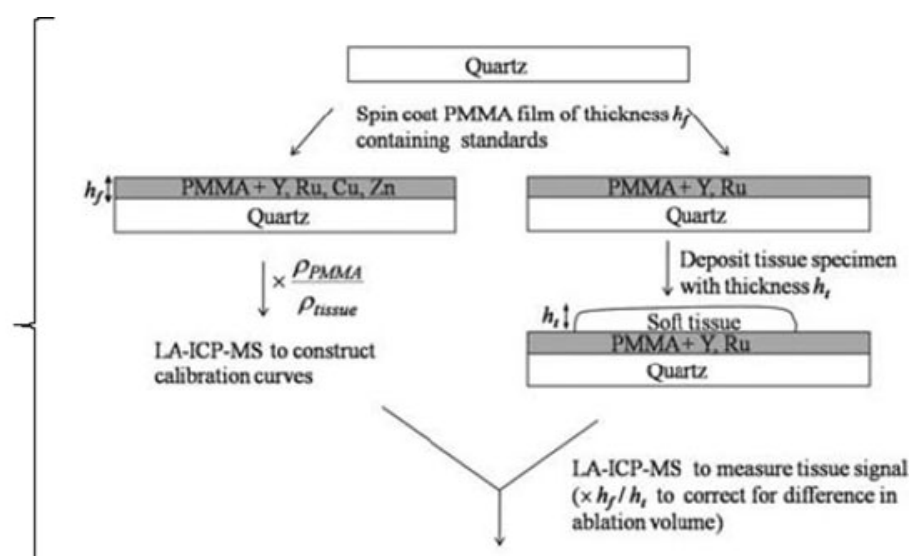

Quantitative tissue $\mathrm{Cu}$ concentration $(\mu \mathrm{g} / \mathrm{g}$ tissue)

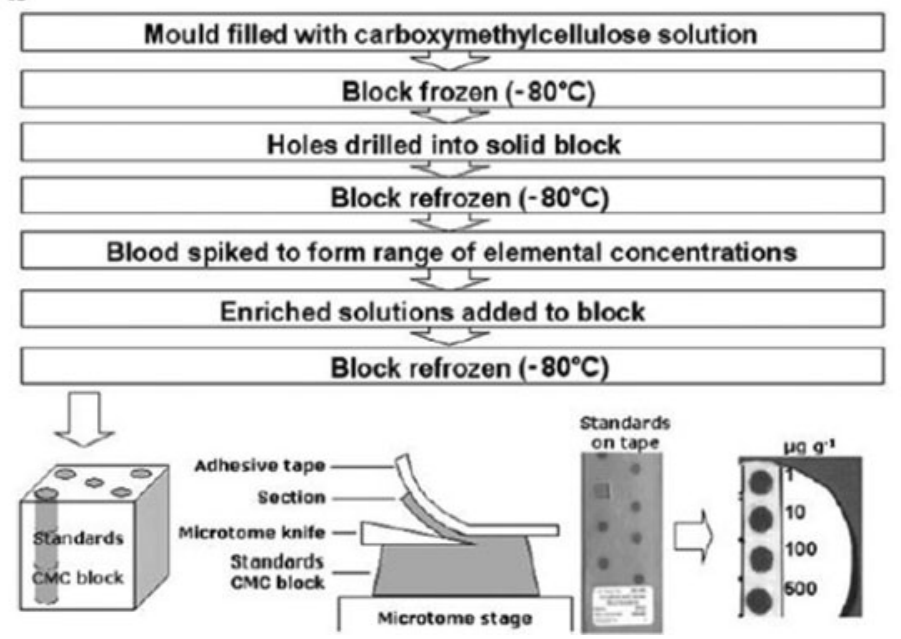

Fig. 3 a-b Schemes of the sample preparation and quantification processes used in two novel calibration strategies for the quantitative elemental imaging of biological soft tissues by LA-ICP-MS. a Internal standard scheme for elemental bioimaging and workflow of the

realising sections of comparable thickness to real samples (in the range of 20-60 $\mu \mathrm{m}$ ). The preparation of thin section standards is presented in Fig. 3b. The proposed approach ensures that samples and standards are matched in terms of not only the chemical matrix but also the physical dimensions (i.e. section thickness). Moreover, lyophilisation, which is the norm in biological CRM production, is used during sample preparation, and this should permit the long-term storage and stability of prepared thin sections.

\section{Analysis of heteroatom-containing proteins by LA-ICP-MS}

The main analytical tools for the analysis of heteroatomtagged proteins include chromatographic or electrophoretic separation of the target biomolecule and their subsequent identification by molecular MS techniques using an electrospray (ESI) or a matrix-assisted laser desorption ionisation quantification process with film standards. b Preparation of frozen matrix-matched standards. From [34, 39]; reproduced with the permission of The Royal Society of Chemistry

(MALDI) source [40-42]. Several alternative elemental MS strategies have been developed to investigate the chemical speciation of the heteroatom bound to the protein, including LA-ICP-MS combined with a high-resolution separation technique.

Gel electrophoresis (GE), with its unique ability to resolve several thousands of proteins in a $2 \mathrm{D}$ run, is a powerful tool that is used routinely in biochemical, medical, and molecular biology laboratories today. Traditionally, detection of the heteroatom of interest relied on autoradiography, so radioactively labelled heteroatoms had to be used. An alternative technique to radioactive detection in the gels is LA-ICP-MS [43], the analytical potential of which has already been demonstrated for the detection of phosphoproteins, selenoproteins, and metalloproteins [41-45]. However, problems with GELA-ICP-MS analysis have been identified, which are related to both sample preparation and electrophoretic separation processes as well as to the laser-matter interaction [46]. In 
spite of the significant number of studies dedicated to the optimisation of sample preparation and the effective separation of proteins (e.g. their stability during GE and postseparation gel treatment), accurate quantitative analysis still remains an important challenge.

\section{Basic studies on gel electrophoresis LA-ICP-MS}

GE-LA-ICP-MS has been applied for the qualitative and quantitative analysis of different types of heteroatomcontaining proteins. Preliminary and basic studies performed over the last decade to assess its analytical potential have, however, focused on elemental analysis. The first work to explore the detection of trace elements in gels after electrophoretic separation using LA-ICP-MS was published in 1998 by Neilsen et al. [47], and centred on the analysis of Co-binding serum proteins. Chéry et al. [48] studied the capabilities of LA-ICP-MS for the detection of selenoproteins in red blood cell extracts and in yeast after 1D and 2D separations using polyacrylamide gels (PAGE). Limits of detection, linearity, and repeatability were evaluated for a whole range of elements using hydrated gels with standard solutions, and they showed that at least semiquantitative detection can be achieved.

A critical prerequisite in metal-protein speciation, however, is to maintain the integrity of heteroatom-protein binding during the whole sample preparation process, including the separation stage. In most applications reported for heteroatom-protein analysis by PAGE-LA-ICP-MS, the analytes were metal- or semimetal-containing proteins such as selenoproteins [48-51], as well as phosphoproteins [52-54]. In such cases the heteroelements are incorporated into the primary protein structure (pure covalent bonds), so the heteroatom-protein bond is not broken during electrophoretic separation. However, in metal-protein binding, the interactions are coordinative, and loss of the metal may occur during electrophoretic separation (especially when using denaturing PAGE). This is a serious pitfall that researchers need to tackle, so the development of new strategies for separating metalloproteins without breaking the metal-protein bond - or at the very least the discovery of accurate and precise quantification strategies that can correct for the possible losses - is urgently needed.

Several authors have reported studies on metal losses in proteins during GE [55-59]. In most cases, the use of native PAGE instead of denaturing PAGE was proposed as the best option to minimise the possible losses. For instance, McLeod's working group [55] investigated the behaviour of Pt-serum binding proteins by LA-ICP-MS after both native and denaturing PAGE. While clear Pt signals were obtained for the proteins of interest using native PAGE, no signals were found after using denaturing separation conditions (see Fig. 4). Those results showed that metalloprotein complexes

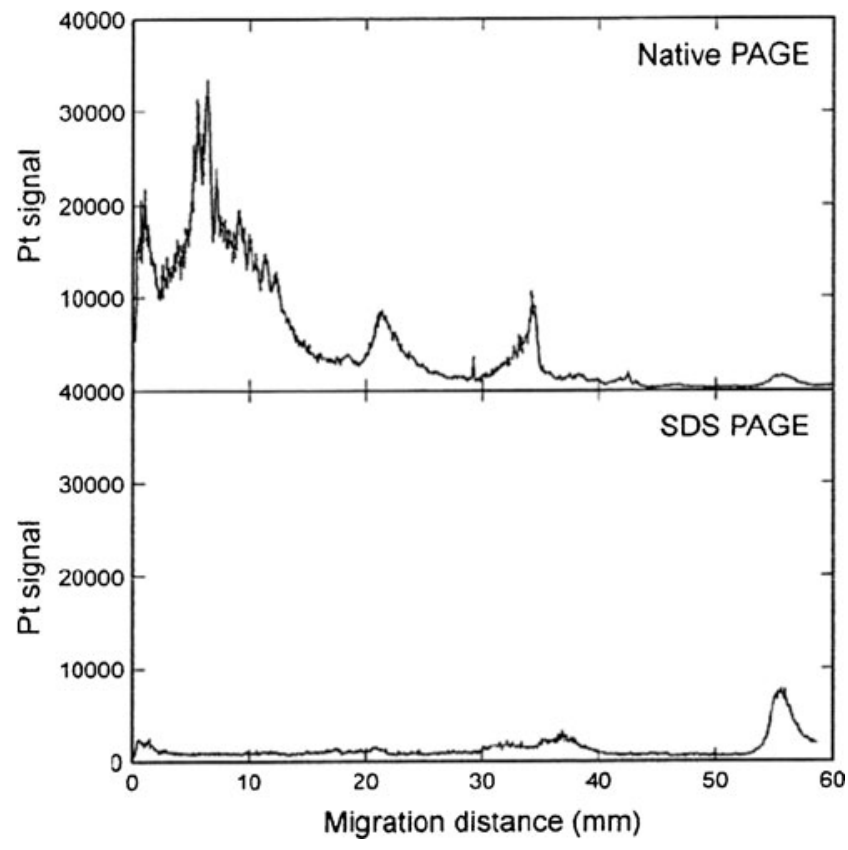

Fig. $4{ }^{195} \mathrm{Pt}$ profile obtained by LA-ICP-MS for the analysis of a Ptenriched blood serum sample using native and denaturing PAGE. From [55]; reproduced with the permission of Wiley-VCH

may have limited conditional stability and, therefore, they should be studied under native rather than denaturing conditions. Moreover, it was found that denaturing PAGE was unsuitable for the absolute quantification of proteins via the metal due to its partial loss during separation (e.g. in coordinative metal-bound proteins, such as $\mathrm{Fe}$ in transferrin) [59]. An alternative approach is the use of GE in combination with electroblotting onto nitrocellulose or PVDF membranes. Proteins can be favourably detected using this technique, not only directly in agarose or polyacrylamide gels, but also after blotting onto membranes. This strategy looks particularly promising for the analysis of phosphoproteins by LA-ICPMS: a matrix separation can be performed to reduce blanks from buffers used for sample preparation, and the proteins are enriched in a thin surface layer. Nevertheless, losses during blotting are often mentioned as a limiting factor as well [60-63], and these are particularly critical when aiming for accurate quantitative analyses.

However, other factors beyond the conditions of the electrophoretic separation can alter the observed metal-protein binding. Several studies have been devoted to investigating the stability of metalloproteins during GE and post-separation gel treatments [64-66]. Raab et al. [64] recently reported a study on the conditions necessary for effective and accurate application of GE-LA-ICP-MS in the analysis of metal-binding proteins. Experimental results showed some important points: (i) it is necessary to use nondenaturing separating conditions for most metalloproteins, since SDS and other denaturing agents can dissociate most metal-protein complexes; (ii) the use of 
unstained gels is recommended, since elemental losses during staining procedures with silver or Coomassie Blue were generally observed; (iii) although several gel drying processes can be employed, the use of glycerol followed by heating proved to be a suitable drying method that did not result in extensive elemental loss; and (iv) elemental contamination of the gel surface should be avoided by using clean-room facilities when available. Therefore, it can be concluded that a separation protocol or speciation workflow that has been specifically selected for proteins cannot be directly extrapolated to metalprotein complexes. The separation conditions and the postseparation gel treatments for each specific application required should be carefully assessed.

\section{Quantification strategies}

Having gathered swathes of qualitative information over the last few decades, it is clear that studies performed in the field of proteomics is now turning quantitative [67]. The natural presence of a heteroatom in a given protein enables the application of elemental MS in the field of heteroatomtagged proteomics, permitting a robust and sensitive approach to protein quantification $[45,55,68]$. In the case of proteins separated by GE using LA-ICP-MS, different calibration strategies have been investigated for protein quantitative analysis. The main proposed approaches have focused on external calibration and the use of isotope dilution mass spectrometry (IDMS).

External calibration methods have traditionally been used for quantitative protein analysis by GE-LA-ICP-MS using protein standards. Several examples can be found in the literature of the analysis of selenoproteins, phosphoproteins, and metalloproteins [40, 49, 52, 69-71]. External calibration is usually carried out by separating a standard model protein present at different concentration levels in the gels. Protein bands are then scanned by the laser beam in the direction of electrophoresis migration and the calibration curve is obtained by integrating LA-ICP-MS profiles of standards. The quantification of a given protein, such as the standard [71] or other proteins [49, 52, 69], has been reported. Also, hydrated gels with standard solutions containing increasing concentrations of the elements of interest have been used for calibration purposes $[48,72]$. The main drawbacks of this strategy are the difficulty involved in ensuring a homogeneous distribution of the heteroelements in the gel, and the need for gel mineralisation afterwards to control the hydration efficiency. In addition, this strategy is clearly not applicable to proteins that are electroblotted onto nitrocellulose or PVDF membranes. Becker et al. [53] proposed a new quantification procedure using a solution-based calibration, where an ultrasonic nebuliser for the nebulisation of calibration standard solutions was coupled to the laser ablation chamber. It should be stressed, however, that such an approach can only be accurate if the particle size distribution of the laser-generated aerosol is well represented by the ultrasonically generated aerosol and is constant during ablation. Moreover, transport, vaporisation, and ionisation must be identical for both types of aerosol-a very difficult task to achieve.

However, these external calibration approaches do not consider the behaviour of proteins under the conditions used for electrophoresis, and do not compensate for possible inhomogeneities in a protein GE spot. Moreover, as stressed above, differences in the sampling rate and aerosol transport efficiency can occur using solution-based calibration, so the laser ablation of solid samples and simultaneous nebulisation of aqueous standards may not match each other. In the search for more accurate alternative quantification strategies, isotope ratio measurements (such as the use of IDMS) have been recently proposed for reliable quantitative protein analysis by GE-LA-ICP-MS. IDMS is internationally regarded as an absolute measurement method that is directly traceable to the International System of Units [73]. In contrast to other calibration strategies, the analytical result is not affected by signal drifts, matrix effects, or analyte losses. Therefore, the quantification of heteroatom-containing proteins by GE-LA-ICPMS can be improved by adding an isotopically enriched protein at the beginning of the sample preparation procedure (so-called species-specific spiking). In this case, possible analyte losses during electrophoretic separation or transformations of the heteroatom-tagged species will not affect the final results. Additionally, LA-ICP-IDMS can also correct for some common fractionation and matrix effects that cannot be controlled using other calibration procedures. So far, however, only a few investigations have assessed the analytical performance of IDMS in combination with GE-LA-ICP-MS [71, 74, 75].

Deitrich et al. [75] reported the use of an isotopically enriched ${ }^{65} \mathrm{Cu},{ }^{68} \mathrm{Zn}$-superoxide dismutase (SOD) complex in an attempt to quantify natural SOD in a spiked liver extract subjected to nondenaturing 1D-PAGE. The stability of the isotopically enriched metal-protein complex was carefully investigated. However, the absolute quantification capabilities of IDMS could not be demonstrated, as the reference materials needed to validate the proposed quantification approach were lacking. Recently, Konz et al. [71] carried out the absolute quantification of a metalloprotein (transferrin, Tf) that was separated by nondenaturing GE using LA-ICP-MS in combination with IDMS. The proposed methodology was based on the use of an isotopically enriched ${ }^{57} \mathrm{Fe}-\mathrm{Tf}$ complex to quantify natural $\mathrm{Tf}$ in human serum. Figure 5 shows the profiles obtained by LA-ICP-MS for ${ }^{56} \mathrm{Fe},{ }^{57} \mathrm{Fe}$, and their isotopic ratio using a mixture of the isotopically enriched ${ }^{57} \mathrm{Fe}$-Tf complex and the sample of interest (a human serum CRM). Additionally, appropriate selection of the laser ablation strategy (single line ablation in 
Fig. 5 Profiles obtained by LA-ICP-MS for ${ }^{56} \mathrm{Fe}^{+},{ }^{57} \mathrm{Fe}^{+}$, and their isotopic ratio, using a mixture of a serum CRM and an isotopically enriched ${ }^{57} \mathrm{Fe}-\mathrm{Tf}$ complex $(13 \mu \mathrm{g}$ natural

Fe-Tf: $\left.14 \mu \mathrm{g}{ }^{57} \mathrm{Fe}-\mathrm{Tf}\right)$. From [71]; reproduced with the permission of the American Chemical Society

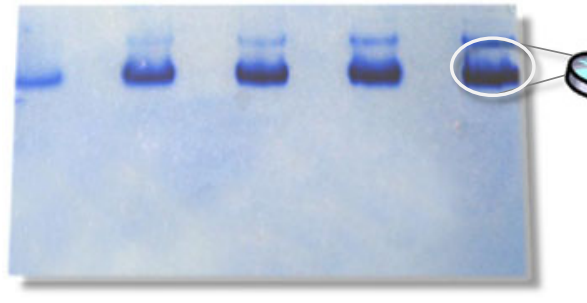

\section{LA-ICP-IDMS}

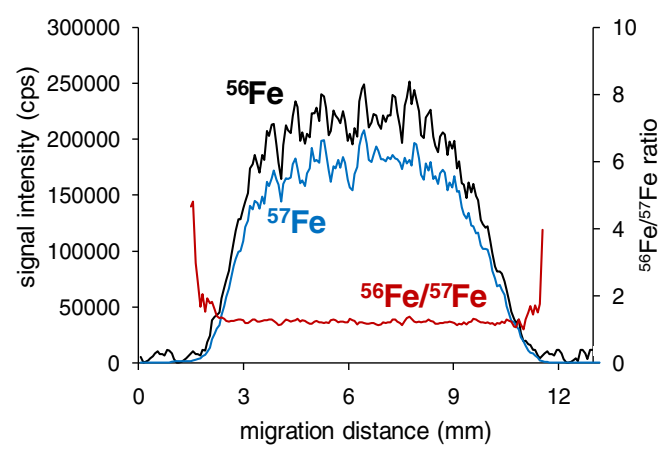

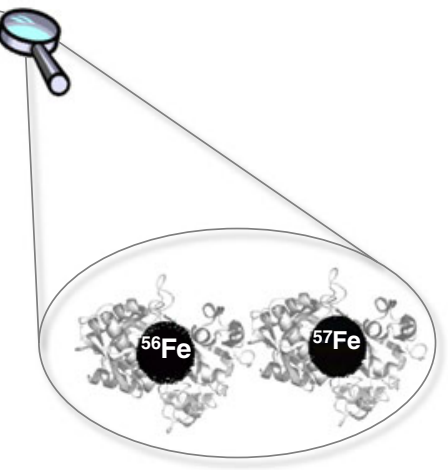

:

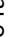
. (n) the direction perpendicular to the electrophoretic migration), the sample preparation method (nondenaturing 1D-PAGE and unstained gels), as well as the data treatment approach (using a least squares method) was found to be crucial to ensuring good precision and accuracy. In contrast to alternative quantification methodologies, calibration curves are unnecessary, and the analysis time is reduced to less than $15 \min [71]$.

\section{Elemental tagging for peptides and proteins in LA-ICP-MS analysis}

As explained in the preceding section, LA-ICP-MS has been successfully used for the measurement of heteroatoms that are naturally directly associated with proteins in tissues (e.g. $\mathrm{P}, \mathrm{S}, \mathrm{Se}$, or metals). However, this technique could also be applied to the analysis of biomolecules that do not naturally have detectable heteroelements present in their structures, by using appropriate labelling strategies [76]. ICP-MSdetectable heteroatom tags can be bioconjugated to biomolecules $[77,78]$ to extend the applicability of "heteroatom (isotope)-tagged, or ICP-MS guided, targeted proteomics" [42]. Different labelling approaches have been investigated for the specific detection of proteins. Although there are many reports on elemental labelling for quantitative peptide and protein analysis in solution by ICP-MS [76, 78], indepth investigations to assess the analytical potential of LA-ICP-MS in combination with labelling approaches are so far scarce.
Protein labelling with element-tagged antibodies for LA-ICP-MS

Immunoassays are currently the most popular analytical technique applied in clinical medicine for the detection and measurement of a large number of biomolecules (i.e. hormones, proteins, enzymes, drugs, nutritional factors, and disease markers) [79]. Immunoassays are simple, rapid, inexpensive, and versatile, and they are very amenable to automation and multiplexing. The capabilities of element-tagged immunoassay technology that employs ICP-MS detection of elementcontaining tags was first reported by Zhang et al. [80] and Baranov et al. [81]. Based on these pioneering works, several concepts and applications have been developed for protein determination by ICP-MS [76, 78]. In this paper, the use of element-tagged antibodies for protein detection by LA-ICP-MS is reviewed.

Lanthanides are the elements that are most widely used for this type of labelling study due to their absence in biological systems and the high stability of their chelate complexes. The labelling of three different polyclonal antibodies with lanthanides to enable the detection of those elements by LA-ICP-MS on Western blot membranes was reported by Waentig et al. [82]. An alternative to this strategy is to use metal clusters as the antibody tag; this approach has the advantage of increasing the detection limits for LAICP-MS measurements because the number of metal atoms per cluster is high [83].

Recent developments in element-tagged immunoassay technology employing ICP-MS have focused on multiplexed 
immunoassays; that is, the detection and quantification of several analytes simultaneously [84]. In homogeneous immunoassays, in which the reagents are adsorbed onto surfaces, many handling steps are performed before the final measurement. The ability of LA to analyse solid samples directly provides a much simpler and faster method of analysing these immunoplates. The potential of immunoassays with elementtagged antibodies (or antigens) employed in combination with LA-ICP-MS detection for multiplexing assays has been demonstrated in several reports $[82,85,86]$. Waentig et al. [86] recently presented a method for the multiparametric and simultaneous quantitative determination of several cytochromes P450 in liver microsomes of untreated and inducertreated (treated with various chemicals, including carcinogens and drugs) rats by LA-ICP-MS. Liver microsomal proteins were separated by SDS-PAGE and subsequently blotted onto nitrocellulose membranes. The resulting blots were simultaneously incubated with five different lanthanide-labelled antibodies, with an additional one used as an IS. The lanes were subsequently ablated by the laser beam and analysed by ICPMS for ${ }^{165} \mathrm{Ho},{ }^{169} \mathrm{Tm},{ }^{175} \mathrm{Lu},{ }^{153} \mathrm{Eu},{ }^{159} \mathrm{~Tb}$, and ${ }^{141} \mathrm{Pr}$. In this way, multiple isoforms of the cytochrome P450 enzymes could be simultaneously determined by LA-ICP-MS.

Protein microarrays provide a powerful multiplexing approach, when used in combination with laser sampling, for detecting proteins, monitoring their expression levels, and investigating protein interactions and functions. The potential of LA-ICP-MS combined with protein microarray technology and multielemental immunotags was recently explored by $\mathrm{Hu}$ et al. [87] for the detection of three model proteins. In that study, $\alpha$-fetoprotein IgG (AFP), carcinoembryonic antigen (CEA), and human IgG were detected on the basis of sandwich-type immunoreactions on a microarray (with $\mathrm{Sm}^{3+}$ labelling for $\mathrm{AFP}, \mathrm{Eu}^{3+}$ labelling for CEA, and $\mathrm{Au}$ nanoparticle labelling for $\mathrm{IgG}$, respectively). Figure 6 shows a laser ablation sampling scheme for detecting three analytes on each spot of a microarray, and the transient signals obtained by LA-ICP-MS from spots of dried droplets on a glass slide when element-tagged antibodies were added. Experimental results proved that LA-ICP-MS can detect multiple proteins in each microarray spot with micrometrerange spatial resolution. Additionally, it was observed that the

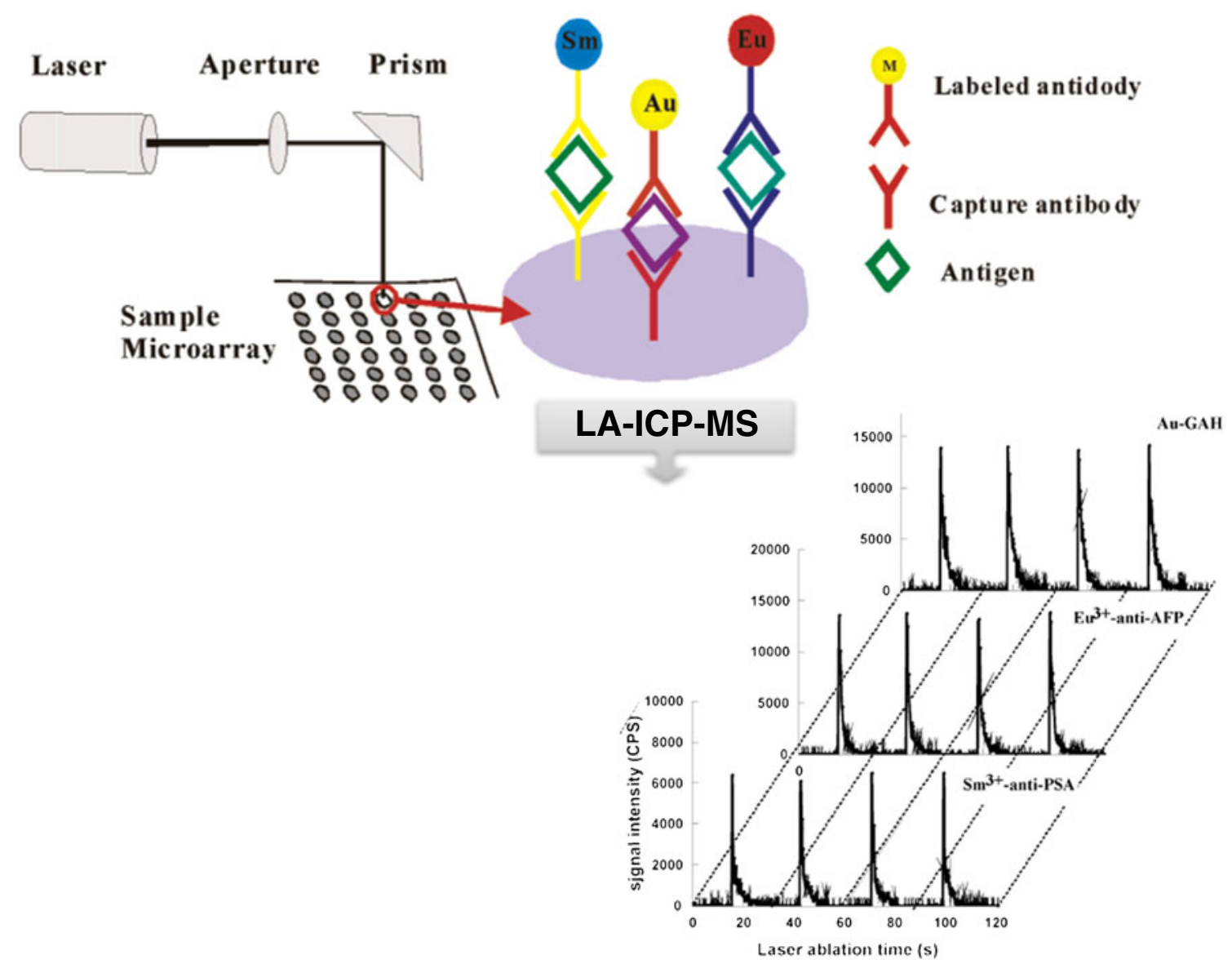

Fig. 6 Scheme for laser ablation sampling of a microarray with multiple analytes in each spot, and the transient signals obtained by LA-ICP-MS from spots of dried droplets on a glass slide when element-tagged antibodies were added: $\mathrm{Eu}^{3+}$-labelled anti-AFP ( $\alpha$-fetoprotein antibody),

$\mathrm{Sm}^{3+}$-labelled anti-PSA (prostate-specific antigen), and colloidal Au-labelled GAH (goat-anti-human IgG). From [87]; reproduced with the permission of the American Chemical Society 
detection limits of the proposed method (reported to lie in the range $0.012-0.2 \mathrm{ng} \mathrm{mL} L^{-1}$ for a protein concentration of $1.0 \mathrm{ng} \mathrm{mL}{ }^{-1}$ ) decreased further still when nanoparticles were used as tags instead of rare-earth ion complexes.

A further application of LA-ICP-MS in this research area is the use of element-tagged immunoassays for imaging purposes, which provides a new strategy for not only mapping peptides and proteins in different types of tissues, but also for their possible quantification [13, 16, 88, 89]. In this vein, Hutchinson et al. [16] reported the imaging of amyloid precursor protein and $A \beta$ peptide in histological sections of a transgenic mouse model of Alzheimer's disease using Eu- and Ni-coupled antibodies. Also, images and the distributions of endogenous metal trace elements in brain sections can be obtained simultaneously with the Eu and Ni measurements. Moreover, combining laser capture microdissection and ICP-MS provides a strategy for microanalysing immunohistochemical sections and an additional route for characterising $A \beta$ deposits of associated trace elements in brain.

The analytical potential of immunohistochemistry combined with LA-ICP-MS has also been demonstrated for the imaging of cancer biomarkers [88, 89]. The distributions of two breast cancer-associated proteins (MUC-1 and HER2) were studied based on multiple line scanning of tissue sections by the laser beam and the subsequent measurement of relevant $\mathrm{Au} / \mathrm{Ag}$-tagged antibodies bound to the tissue. Results showed a good correlation between optical microscopy and LA-ICP-MS measurements in terms of feature information, and permitted analysis with a high sensitivity and sufficient resolution to permit fine-scale feature mapping at the cellular level.

Protein labelling using small molecules that form covalent bonds

As an alternative to element-tagged antibodies, proteins can be labelled by iodination, mercury-containing compounds, or metal chelates. Iodination has been widely used to label peptides and proteins, and has proven to be a simple, cheap, and efficient method based on the covalent binding of a heteroatom to a protein for solution ICP-MS detection. The reaction is based on the electrophilic substitution of iodine in histidine and tyrosine [90]. Different protocols for protein iodination have been applied for the LA-ICP-MS detection of intact proteins that have been separated by SDS-PAGE and electroblotted onto nitrocellulose membrane $[91,92]$. The iodination efficiencies of single proteins (lysozyme, BSA, cytochrome $\mathrm{C} 450$, and $\beta$-casein), a whole proteome (microsomal proteome of rats), and antibodies (anti-bovine casein, anti-BSA) with potassium triiodide have been demonstrated, with minimal losses of antigen properties and antibody-binding ability observed [92]. Moreover, compared with previous experiences applying lanthanide-labelled antibodies for the detection of antigens, the iodine labelling of a whole proteome or of given markers looks very promising. Recently, Giesen et al. [13] reported the first application of iodination for imaging single cells in tissue sections by LA-ICP-MS. This method provides information on cell morphology. Mercury compounds can also be employed as protein ICP-MS tag reagents, since mercury can form highly stable covalent bonds with free sulfhydryl groups in proteins, as presented by Kutscher et al. [74]. In this work, the potential of a mercury tag for the sensitive detection of ovalbumin protein separated on PAGE gels, after labelling with $p$-hydroxymercuribenzoic acid (pHMB) and finally using LA-ICP-MS, was studied in detail. For quantification purposes, the use of label-specific IDMS (using ${ }^{199} \mathrm{Hg}$-enriched pHMB) was found to improve the precision and accuracy of the quantitative results obtained.

An alternative labelling approach for the specific detection of proteins is to use metal chelates. A metal ion can be attached to a biological molecule via bifunctionalised chelating reagents; these contain a metal-chelating group (metal tag) and a second functional group that forms a covalent bond to the desired molecule (bioconjugation). Among several metal chelates described in the literature, lanthanide DOTA chelate (1,4,7,10-tetraazacyclododecane-1,4,7,10-tetraacetic acid) seems to be the most versatile [77]. Such a bifunctional chelate has been successfully applied by Jakubowski et al. for the multielement labelling of proteins separated by SDS-PAGE [93]. Detection was performed by LA-ICPMS after electroblotting the target proteins onto nitrocellulose membranes. Two different proteins (BSA and hen egg white lysozyme) were labelled with the commercially available chelating compound DOTA containing stable isotopes of lanthanides (labelling with $\mathrm{Eu}, \mathrm{Tb}$, and Ho was successfully performed and studied). Compared to reported strategies that use iodine labelling $[13,92]$, the DOTA approach was found to be more laborious and time-consuming, but it is still promising, as it can be used to develop multiplexed procedures for proteins (and antibodies).

\section{Conclusions}

In recent years, LA-ICP-MS has been shown to be a powerful analytical tool for imaging (mapping) the distributions of metals and nonmetals in thin sections of biological tissues. Its high sensitivity, excellent spatial resolution, absolute quantification capability, robustness, and ability to carry out isotope ratio measurements with great accuracy are opening new avenues for the application of LA-ICP-MS in the life sciences [94-96].

Various quantification strategies have been reported so far, and there is no consensus regarding a preferred approach as yet. This is particularly important in relation to the growing 
number of bioimaging applications that have appeared in the literature lately [97]. Thus, there is a clear need to develop reliable methodologies for LA-ICP-MS robust elemental determinations and to search for universal calibration methods for the absolute quantitative imaging of heteroatoms in tissues, and there is indeed a trend for studies focussing on these goals.

Concerning protein analysis, information provided by elemental LA-ICP-MS has been demonstrated to be complementary to that achieved by present molecular MS instruments (i.e. MALDI-MS or ESI-MS) [2, 98, 99]. It is worth highlighting, however, that combining LA-ICP-MS and protein fingerprinting methods ("integrated speciation" by heteroatom-tagged proteomics) helps to overcome some of the current limitations of the approaches more commonly used in proteomics. Information from both molecular and elemental mass spectrometry can be applied to discover new biomarkers and to study metalbiomolecule complexes and their interactions. In addition, new developments in imaging MS enable the spatial resolution of metalloproteins in tissues to be investigated. As an example, investigating interactions of proteins with small molecules by combining LA-ICP-MS and typical organic MS techniques will lead to precious information on the metal loading of proteins in diseased states, the identification of drug targets, and the development of new targeted proteomics approaches (e.g. via the quantification of appropriate biomarkers). It is expected that LA-ICP-MS will offer new insights into the molecular bases of diseases related to metals and other heteroatoms, and the differences between between normal and altered (disease) states. Moreover, multiplexed analytical methods based on LA-ICP-MS, which use metal-containing labels as elemental tags and possess great potential for the quantification of several biomarkers in microarrays, are currently being developed. Finally, LA-ICP-MS could provide a useful tool for obtaining valuable information for the early detection (diagnosis) and treatment (drug targets) of diseases, including cancer and neurodegenerative conditions [100].

Acknowledgements Financial support from "Plan Nacional de I + D + I" (Spanish Ministry of Science and Innovation or MICINN and the EU FEDER program) through MAT2010-20921-C02 and PCTI Asturias through the project FC-09-EQUIP09-29 is acknowledged. I. Konz and B. Fernandez are thankful for financial support from FPU and "Juan de la Cierva" Programs from the Ministry of Education and MICINN, respectively.

\section{References}

1. Mounicou S, Szpunar J, Lobinski R (2009) Chem Soc Rev 38:1119-1138

2. Careri M, Mangia A (2011) Anal Bioanal Chem 399:2585-2595

3. Bettmer J (2010) Anal Bioanal Chem 397:3495-3502

4. Koch J, Günther D (2011) Appl Spectrosc 65:155A-162A

5. Becker JS (2007) Inorganic mass spectrometry: principles and applications. Wiley, Chichester
6. Becker JS, Zoriy M, Matusch A, Wu B, Salber D, Palm C, Becker JS (2010) Mass Spectrom Rev 29:156-175

7. Qin Z, Caruso JA, Lai B, Matusch A, Becker JS (2011) Metallomics 3:28-37

8. Zoriy M, Matusch A, Spruss T, Becker JS (2007) Int J Mass Spectrom 260:102-106

9. Becker JS, Breuer U, Hsieh H-F, Osterholt T, Kumtabtim U, Wu B, Matusch A, Caruso JA, Qin Z (2010) Anal Chem 82:9528-9533

10. Hare D, Burger F, Austin C, Fryer F, Grimm R, Reedy B, Scolyer RA, Thompson JF, Doble P (2009) Analyst 134:450-453

11. Hare D, Tolmachev S, James A, Bishop D, Austin C, Fryer F, Doble P (2010) Anal Chem 82:3176-3182

12. Sarafanova AG, Todorov TI, Kajdacsy-Ballac A, Gray MA, Macias V, Centeno JA (2008) J Trace Elem Med Biol 22:305-314

13. Giesen C, Waentig L, Mairinger T, Drescher D, Kneipp J, Roos PH, Panneab U, Jakubowski N (2011) J Anal At Spectrom 26:2160-2165

14. Feldmann J, Kindness A, Ek P (2002) J Anal At Spectrom $17: 813-818$

15. Kindness A, Sekaran CN, Feldmann J (2003) Clin Chem 49:1916-1923

16. Hutchinson RW, Cox AG, McLeod CW, Marshall PS, Harper A, Dawson EL, Howlett DR (2005) Anal Biochem 346:225-233

17. Hare D, Reedy B, Grimm R, Wilkins S, Volitakis I, George JL, Cherny RA, Bush AI, Finkelstein DI, Doble P (2009) Metallomics 1:53-58

18. Hare DJ, George JL, Grimm R, Wilkins S, Adlard PA, Cherny RA, Bush AI, Finkelstein DI, Doble P (2010) Metallomics 2:745-753

19. Zoriy MV, Dehnhardt M, Reifenberger G, Zilles K, Becker JS (2006) Int J Mass Spectrom 257:27-33

20. Dobrowolska J, Dehnhardt M, Matusch A, Zoriy M, PalomeroGallagher N, Koscielniak P, Zilles K, Becker JS (2008) Talanta 74:717-723

21. Zoriy M, Dehnhardt M, Matusch A, Becker JS (2008) Spectrochim Acta Part B 63:375-382

22. Matusch A, Bauer A, Becker JS (2011) Int J Mass Spectrom 307:240-244

23. Becker JS, Matusch A, Becker JS, Wu B, Palm C, Becker AJ, Salber D (2011) Int J Mass Spectrom 307:3-15

24. Matusch A, Depboylu C, Palm C, Wu B, Höglinger GU, Schäfer MK-H, Becker JS (2010) J Am Soc Mass Spectrom 21:161-171

25. Becker JS, Zoriy MV, Pickhardt C, Palomero-Gallagher N, Zilles K (2005) Anal Chem 77:3208-3216

26. Zoriy MV, Kayser M, Izmer A, Pickhardt C, Becker JS (2005) Int J Mass Spectrom 242:297-302

27. Becker JS, Zoriy MV, Dehnhardt M, Pickhardt C, Zilles K (2005) J Anal At Spectrom 20:912-917

28. Lear J, Hare D, Adlard P, Finkelstein D, Doble P (2012) J Anal At Spectrom 27:159-164

29. Gholap DS, Izmer A, De Samber B, van Elteren JT, Selih VS, Evens R, De Schamphelaere K, Janssen C, Balcaen L, Lindemann I, Vincze L, Vanhaecke F (2010) Anal Chim Acta 664:19-26

30. Wang HAO, Grolimund D, Van Loon LR, Barmettler K, Borca CN, Aeschlimann B, Günther D (2011) Anal Chem 83:6259-6266

31. Jackson B, Harper S, Smith L, Flinn J (2006) Anal Bioanal Chem 384:951-957

32. Todoli JL, Mermet JM (1998) Spectrochim Acta Part B 53:16451656

33. Austin C, Fryer F, Lear J, Bishop D, Hare D, Rawling T, Kirkup L, McDonagh A, Doble P (2011) J Anal At Spectrom 26:1494-1501

34. Austin C, Hare D, Rawling T, McDonagh AM, Doble P (2010) J Anal At Spectrom 25:722-725

35. Pozebon D, Dressler VL, Mesko MF, Matusch A, Becker JS (2010) J Anal At Spectrom 25:1739-1744

36. Becker JS, Zoriy M, Becker JS, Dobrowolska J, Dehnhardt M, Matusch A (2007) Phys Stat Sol 4:1775-1784 
37. Myroslav V, Zoriy M, Becker JS (2007) Int J Mass Spectrom 264:175-180

38. Moreno-Gordaliza E, Giesen C, Lazaro A, Esteban-Fernández D, Humanes B, Canas B, Panne U, Tejedor A, Jakubowski N, Gómez-Gómez MM (2011) Anal Chem 83:7933-7940

39. Pugh JAT, Cox AG, McLeod CW, Bunch J, Whitby B, Gordon B, Kalber T, White E (2011) J Anal At Spectrom 26:1667-1673

40. Ballihaut G, Pécheyran C, Mounicou S, Preud'homme H, Grimaud R, Lobinski R (2007) Trends Anal Chem 26:183-190

41. Becker JS, Lobinski R, Becker JS (2009) Metallomics 1:312-316

42. Sanz-Medel A (2008) Anal Bioanal Chem 391:885-894

43. Cornelis R, Caruso JA, Crews H, Heumann KG (2003) Handbook of elemental speciation, 1st edn. Wiley, Chichester

44. Grebe M, Profrock D, Kakuschke A, Broekaert JAC, Prange A (2011) Metallomics 3:176-185

45. Bettmer J, Montes-Bayón M, Encinar JR, Fernández-Sánchez ML, De La Campa MDRF, Sanz-Medel A (2009) J Proteomics 72:989-1005

46. Sussulini A, Becker JS (2011) Metallomics 3:1271-1279

47. Neilsen JL, Abildtrup A, Christensen J, Watson P, Cox A, McLeod CW (1998) Spectrochim Acta Part B 53:339-345

48. Chéry CC, Günther D, Cornelis R, Vanhaecke F, Moens L (2003) Electrophoresis 24:3305-3313

49. Fan TWM, Pruszkowski E, Shuttleworth S (2002) J Anal At Spectrom 17:1621-1623

50. Tastet L, Schaumlöffel D, Lobinski R (2008) J Anal At Spectrom 23:309-317

51. Bianga J, Ballihaut G, Pecheyran C, Touat Z, Preud'homme H, Mounicou S, Chavatte L, Lobinski R, Szpunar J (2012) J Anal At Spectrom 27:25-32

52. Marshall P, Heudi O, Bains S, Freeman HN, Abou-Shakra FR, Reardon K (2002) Analyst 127:459-461

53. Becker JS, Boulyga SF, Becker JS, Pickhardt C, Damoc E, Przybylski M (2003) Int J Mass Spectrom 228:985-997

54. Becker JS, Zoriy MV, Przybylski M, Becker JS (2007) Int J Mass Spectrom 261:68-73

55. Ma R, McLeod CW, Tomlinson K, Poole RK (2004) Electrophoresis 25:2469-2477

56. Chéry CC, Moens L, Cornelis R, Vanhaecke F (2006) Pure Appl Chem 78:91-103

57. Polatajko A, Azzolini M, Feldmann I, Stuezel T, Jakubowski N (2007) J Anal At Spectrom 22:878-887

58. Becker JS, Mounicou S, Zoriy MV, Becker JS, Lobinski R (2008) Talanta 76:1183-1188

59. Garijo Añorbe M, Messerschmidt J, Feldmann I, Jakubowski N (2007) J Anal At Spectrom 22:917-924

60. Nesatyy VJ, Ross NW (2002) Analyst 127:1180-1187

61. Wind M, Feldmann I, Jakubowski N, Lehmann WD (2003) Electrophoresis 24:1276-1280

62. Venkatachalam A, Koehler CU, Feldmann I, Lampen P, Manz A, Roos PH, Jakubowski N (2007) J Anal At Spectrom 22:1023-1032

63. Pedrero Z, Madrid Y, Camara C, Schram E, Luten JB, Feldmann I, Waentig L, Hayend H, Jakubowski N (2009) J Anal At Spectrom 24:775-784

64. Raab A, Pioselli B, Munro C, Thomas-Oates J, Feldmann J (2009) Electrophoresis 30:303-314

65. Jiménez MS, Gomez MT, Rodriguez L, Martinez L, Castillo JR (2009) Anal Bioanal Chem 393:699-707

66. Jiménez MS, Rodriguez L, Gomez MT, Castillo JR (2010) Talanta 81:241-247

67. Ong S-E, Mann M (2005) Nat Chem Biol 1:252-262
68. Sanz-Medel A, Montes-Bayón M, De La Campa MDRF, Encinar JR, Bettmer J (2008) Anal Bioanal Chem 390:3-16

69. Ballihaut G, Claverie F, Pécheyran C, Mounicou S, Grimaud R, Lobinski R (2007) Anal Chem 79:6874-6880

70. Bandura DR, Ornatsky OI, Liao L (2004) J Anal At Spectrom 19:96-100

71. Konz I, Fernández B, Fernández ML, Pereiro R, Sanz-Medel A (2011) Anal Chem 83:5353-5360

72. Binet MRB, Ma R, McLeod CW, Poole RK (2003) Anal Biochem 318:30-38

73. Heumann KG (2004) Anal Bioanal Chem 378:318-329

74. Kutscher DJ, Fricker MB, Hattendorf B, Bettmer J, Günther D (2011) Anal Bioanal Chem 401:2691-2698

75. Deitrich CL, Braukmann S, Raab A, Munro C, Pioselli B, Krupp EM, Thomas-Oates JE, Feldmann J (2010) Anal Bioanal Chem 397:3515-3524

76. Bettmer J, Jakubowski N, Prange A (2006) Anal Bioanal Chem 386:7-11

77. Bettmer J, Montes Bayón M, Ruiz Encinar J, Fernández Sánchez ML, Fernández de la Campa MR, Sanz Medel A (2009) J Proteomics 72:989-1005

78. Tholey A, Schaumlöffel D (2010) TrAC Trends Anal Chem 2:399-408

79. Wild D (2005) The immunoassay handbook. Elsevier, Oxford

80. Zhang C, Wu F, Zhang Y, Wang X, Zhang X (2001) J Anal At Spectrom 16:1393-1396

81. Baranov VI, Quinn Z, Bandura DR, Tanner SD (2002) Anal Chem 74:1629-1636

82. Waentig L, Roos PH, Jakubowski N (2009) J Anal At Spectrom 24:924-933

83. Muller SD, Diaz-Bone RA, Felix J, Goedecke W (2005) J Anal At Spectrom 20:907-911

84. Quinn ZA, Baranov VI, Tanner SD, Wrana JL (2002) J Anal At Spectrom 17:892-896

85. Roos PH, Venkatachalam A, Manz A, Waentig L, Koehler CU, Jakubowski N (2008) Anal Bioanal Chem 392:1135-1147

86. Waentig L, Jakubowski N, Roos PH (2011) J Anal At Spectrom $26: 310-319$

87. Hu S, Zhang S, Hu Z, Xing Z, Zhang X (2007) Anal Chem 79:923-929

88. Seuma J, Bunch J, Cox A, McLeod C, Bell J, Murray C (2008) Proteomics 8:3775-3784

89. Giesen C, Mairinger T, Khoury L, Waentig L, Jakubowski N, Panne U (2011) Anal Chem 83:8177-8183

90. Markwell MAK (1982) Anal Biochem 125:427-432

91. Jakubowski N, Messerschmidt J, Garijo-Añorbe M, Waentig L, Hayen H, Roos PH (2008) J Anal At Spectrom 23:1487-1496

92. Waentig L, Jakubowski N, Hayen H, Roos PH (2011) J Anal At Spectrom 26:1610-1618

93. Jakubowski N, Waentig L, Hayen H, Venkatachalam A, von Bohlen A, Roos PH, Manz A (2008) J Anal At Spectrom 23:1497-1507

94. Murphy RC, Merrill AH (2011) Biochim Biophys Acta 1811:635-636

95. Eberlin LS, Liu X, Ferreira CR, Santagata S, Agar NYR, Cooks RG (2011) Anal Chem 83:8366-8371

96. Seeley EH, Caprioli RM (2008) Proteomics Clin Appl 2:1435-1443

97. Seeley EH, Caprioli RM (2012) Anal Chem 84:2105-2110

98. Castellino S, Groseclose MR, Wagner D (2011) Bioanalysis 3:2427-41

99. Matusch A, Fenn LS, Depboylu C, Klietz M, Strohmer S, McLean JA, Becker JS (2012) Anal Chem 84:3170-3178

100. Becker JS, Salber D (2010) TrAC Trends Anal Chem 29:966-979 